\title{
Antioxidant Activities and Protective Effects on Hyperlipidemic Mice of Chinese Oat Rice Wine
}

\author{
Lu TU ${ }^{1}$, AiLi WANG ${ }^{1}$, ChangZhong REN ${ }^{2}$, ZaiGui LI ${ }^{1 *}$ and Masayoshi SAITO \\ ${ }^{1}$ College of Food Science \& Nutritional Engineering, China Agricultural University (17 Qinghua \\ Dong Lu, Haidian, Beijing, 100083, China) \\ ${ }^{2}$ Baicheng Academy of Agricultural Sciences (Jilin, P. R. China, 137000) \\ ${ }^{3}$ Program Director, Japan International Research Center for Agricultural Sciences (Tsukuba, Ibaraki \\ 305-8686, Japan)
}

\begin{abstract}
Antioxidant activities and the lipid-decreasing ability of oat (Avena sativa L.) rice wine were investigated. Oat rice wine showed stronger metal chelating capacity, reducing power, and inhibition of lipid peroxidation than glutinous rice wine. The concentration of polyphenols $\left(153.74 \mu \mathrm{g} \mathrm{ml}^{-1}\right)$ in oat rice wine also exceeded that in glutinous rice wine. Oat rice wine of the three dosages in this experiment increased superoxide dismutase (SOD) and glutathione peroxidase (GSH-PX) activities, while decreasing the malondialdehyde (MDA) content, total blood cholesterol and triglyceride level, alanine aminotransferase (ALT) and aspartate aminotransferase (AST) activities in high-fatty mice. A medium dose $\left(0.3 \mathrm{ml} \mathrm{d}^{-1}\right)$ of oat rice wine could reduce the contents of blood lipid and prevent liver damage. Oat rice wine also manifested stronger antioxidant activity than glutinous rice wine and was effective in decreasing the total cholesterol and triglyceride level in blood and ameliorating the fatty liver in vivo.
\end{abstract}

Discipline: Food Technology

Additional key words: liver damage, total cholesterol, triglyceride

\section{Introduction}

Rice wine is well-known in China as Huangjiu and in Japan as Shoko-shu over a long history of about 4,000 years, and now honored as a national banquet wine in China due to its unique flavor and low alcoholicity ${ }^{34}$. Rice wine also has medical uses in Chinese traditional medicine. Its healthy effects have been studied over the last decade and it is claimed to have beneficial effects on preventing cancer, aging and cardiovascular diseases ${ }^{28}$.

The basic brewing processes of rice wine include activation of distiller's microorganism (such as yeast, Aspergillus spp., Rrhizopus spp., Mucor spp., Monascus spp., acetic acid bacteria, lactic acid bacteria ${ }^{33}$ ), steaming raw materials and fermentation which produce ethanol and other nutrients. The flavor varies widely among different rice wines, and largely depends on the microorganisms used in the brewing process. Hongqu, also called red yeast rice or red fermented rice by Monascus spp., is used as a traditional medicine which has benefited digestion and vascular functions for many centuries. The monacolins from Hongqu reportedly exhibit a cholesterol-lowering action by inhibiting the HMG-CoA reductase, similar to the commercial statin drug ${ }^{18}$. Monacolins are a type of polyketides with the ability to inhibit cholesterol synthesis and lower plasma cholesterol levels independent of diet. One of the monacolins (Monacolin K) has an identical chemical structure to Lovastatin, which is widely sold as a prescription cholesterol-lowering drug, but the other monacolins in Hongqu may also have cholesterol-lowering activity. Moreover, Hongqu is considered to be one of

\footnotetext{
Abbreviations

ALT, alanine aminotransferase; AST, aspartate aminotransferase; SOD, superoxide dismutase; GSH-Px, glutathione peroxidase; MDA, malondialdehyde; HMG-CoA, HMGCoAreductase; TC, total cholesterol; TG, triglyceride; ROS, reactive oxygen; VE, vitamin E; BHA, butyl hydroxy anisol;. EDTA, ethylene diamine tetraacetic acid.
}

*Corresponding author: e-mail lizg@cau.edu.cn

Received 21 March 2012; accepted 24 September 2012. 
the most promising natural lipid-lowering substances for its great effect against hypertension ${ }^{18}$.

Glutinous is the main traditional material used in rice wine production, but many other minor grains are also now used as raw materials. Oat is rich in nutrients, such as unsaturated fatty acids, soluble fiber and saponin, which play key roles in reducing the content of triglycerides and cholesterol in the blood and hence the risk of cardiovascular disease ${ }^{25}$. Recently, avenanthramides, which are an important component of oats, were shown to have strong inhibitory effects on an oleic acid-induced fatty liver model in vitro ${ }^{1}$. Accordingly, rice wine made from oats may have some different functions other than traditional rice wines.

The aim of this work was to measure the antioxidant properties of oat rice wines in vitro and in vivo, as well as the effects on hyperlipemia and fatty liver of mice. The enzyme activities of superoxide dismutase (SOD) and glutathione peroxidase (GSH-PX), and the values of malondialdehyde (MDA) in the liver and blood serum of mice were also detected to evaluate antioxidant activity. The enzyme activities of Alanine aminotransferase (ALT) and aspartate aminotransferase (AST) were determined to evaluate the influence on liver damage.

\section{Material and methods}

\section{Materials}

Glutinous rice wine fermented with Hongqu was provided by Zhejiang Dongyang Rongxin wine Co., Ltd. Oat rice wine was made in the laboratory: an oat-water mixture $(1: 1.2, \mathrm{w} / \mathrm{w})$ was steamed at $100^{\circ} \mathrm{C}$ for $40 \mathrm{~min}$ and cooled to room temperature $\left(25^{\circ} \mathrm{C}\right)$. Hongqu $(10 \%$ of oat weight) was mixed with water at the rate of $1: 1(\mathrm{w} / \mathrm{w})$, and then activated at $23^{\circ} \mathrm{C}$ for $4 \mathrm{~h}$. To produce nutrients and liquefy the oats to improve fermentation, the Hongqu mixture was then inoculated into the cooked glutinous or oats, and the ratio of the mixture to seed was 1 to 10 . The fermentation took place in an incubator at $23-25^{\circ} \mathrm{C}$. The alcohol content of the oat rice wine reached $30 \%(\mathrm{v} / \mathrm{v})$ after 45 days of fermentation.

\section{Total polyphenol content of rice wines}

The total polyphenol content in oat rice wine was determined using the Folin-Ciocalteu method $^{29}$, with gallic acid as the guide sample. Oat rice wine $(1 \mathrm{ml})$ at an appropriate concentration (diluted 46 times with distilled water) was added sequentially with $1.0 \mathrm{ml}$ Folin-Ciocalteu reagent, whereupon $3.0 \mathrm{ml}$ of $2 \% \mathrm{Na}_{2} \mathrm{CO}_{3}$ was added to the solution after $3 \mathrm{~min}$ and mixed uniformly. The absorbance of the mixture was measured at $765 \mathrm{~nm}$ by a spectrophotometer (UV-2100, UNICO, USA) after $2 \mathrm{~h}$.
The results were expressed as mg gallic acid equivalents $\mathrm{ml}^{-1}$ rice wine. Glutinous rice wine was used as a control, compared to oat rice wine.

\section{Total antioxidant activity}

Total antioxidant activities of wines were determined based on the thiocyanate method ${ }^{2,17}$. The solution, which contained $200 \mu \mathrm{l}$ of rice wine in $2.5 \mathrm{ml}$ of $0.04 \mathrm{M}$ potassium phosphate buffer ( $\mathrm{pH} 7.0$ ), was added to $2.5 \mathrm{ml}$ of linoleic acid emulsion in a $0.04 \mathrm{M}$ potassium phosphate buffer ( $\mathrm{pH} 7.0$ ). Conversely, the $5.0 \mathrm{ml}$ control was composed of $2.5 \mathrm{ml}$ of linoleic acid emulsion and $2.5 \mathrm{ml}$ of $0.04 \mathrm{M}$ potassium phosphate buffer ( $\mathrm{pH}$ 7.0). Fifty milliliters of linoleic acid emulsion were prepared with 350 $\mathrm{mg}$ of Tween-20 and $310 \mu \mathrm{l}$ of linoleic acid, whereupon $0.04 \mathrm{M}$ of potassium phosphate buffer ( $\mathrm{pH} 7.0$ ) was added to top up the volume. The mixed solution $(5 \mathrm{ml})$ was then incubated at $37^{\circ} \mathrm{C}$ in darkness. A sample of $100 \mu 1$, which was extracted from the incubated solution at intervals of $12 \mathrm{~h}$, was added to $4.7 \mathrm{ml}$ ethanol (75\%), and then reacted with $20 \mathrm{mM} \mathrm{FeCl}_{2}$ (in $3.5 \% \mathrm{HCl}$ ) and $30 \%$ thiocyanate. The peroxide level was determined by reading the absorbance of the previous reaction solution at $500 \mathrm{~nm}$ in a spectrophotometer (UV-2100, UNICO, USA). Peroxide was produced in the linoleic acid oxidation process, which could oxidize $\mathrm{Fe}^{2+}$ to $\mathrm{Fe}^{3+}$. The complex, which was predicted by the reaction between $\mathrm{Fe}^{3+}$ and the $\mathrm{SCN}^{-}$, had the biggest absorbance at $500 \mathrm{~nm}$. Inhibition of lipid peroxidation in percent was expressed in the form of antioxidant activity.

\section{Reducing capacity}

The reducing capacity was determined by the method of Oyaizu ${ }^{20}$. Different volumes $(50,100,200 \mu \mathrm{l})$ of wine samples in $1 \mathrm{ml}$ of distilled water were mixed with $2.5 \mathrm{ml}$ of a $0.2 \mathrm{M}$ potassium phosphate buffer ( $\mathrm{pH}$ 6.6) and $2.5 \mathrm{ml}$ of $1 \%$ potassium ferricyanide $\left[\mathrm{K}_{3} \mathrm{Fe}(\mathrm{CN})_{6}\right]$. The mixture was incubated at $50^{\circ} \mathrm{C}$ for $20 \mathrm{~min}$. Aliquots $(2.5 \mathrm{ml})$ of $10 \%$ trichloroacetic acid were added to the mixture, which was then centrifuged for $10 \mathrm{~min}$ at $1000 \times$ g (TD4A, Changsha, China). The upper layer of the solution $(2.5 \mathrm{ml})$ was mixed with $2.5 \mathrm{ml}$ distilled water and $0.5 \mathrm{ml}$ of $0.1 \% \mathrm{FeCl}_{3}$, and the absorbance was measured at $700 \mathrm{~nm}$ in a spectrophotometer.

\section{Chelating activity of ferrous ions}

The chelating activity of oat rice wine on $\mathrm{Fe}^{2+}$ was measured using the Decker and Welch method ${ }^{5}$. One milliliter of solution containing different volumes of rice wine $(200,500,1,000 \mu \mathrm{l})$ was mixed with $4.7 \mathrm{ml}$ of distilled water and then reacted with $0.1 \mathrm{ml}$ of $2 \mathrm{mM} \mathrm{FeCl}_{2}$ and $0.2 \mathrm{ml}$ of $5 \mathrm{mM} 3$-(2-pyridyl) -5,6-bis (4-phenyl-sul- 
fonic acid)-1,2,4-triazine (ferrozine) respectively for 20 $\min$. The absorbance was measured at $562 \mathrm{~nm}$ in a spectrophotometer. The lower the absorbance of the reaction mixture, the higher the chelating activity. Ethylene diamine tetraacetic acid (EDTA) (1 g/l) and citric acid (1 $\mathrm{g} / \mathrm{l})$ were used as positive controls ${ }^{8}$.

\section{Animals and diets}

Sixty Kun Ming male mice (body weight (b.w.) 18$22 \mathrm{~g}, 9$ weeks' old) were purchased from the medical college of Xi'an Jiaotong University, Xi'an, China. The mice were housed individually in polycarbonate cages and acclimatized in a temperature- and humidity-controlled room $\left(23 \pm 1{ }^{\circ} \mathrm{C}, \mathrm{RH}=50 \sim 60 \%\right)$ with a 12-h light/dark cycle for 1 week. The mice were given free access to food and water. These mice were then divided randomly into two groups, referred to as the normal control group $(n=10)$ and the fatty model group $(n=50)$. The mice of the normal control group were fed with basic forage and the fatty model group was fed with a high caloric diet ad libitum. This high caloric diet comprised the following ingredients: $88.5 \%$ basic forage (from the medical college of Xi'an Jiaotong University, Xi'an, China, protein 19.84\%, lipid $4.60 \%$, ash $9.33 \%$, starch $49.75 \%$ and dietary fiber $16.43 \%$ mainly from soybean protein, oil and corn starch); $10 \%$ lard oil; $1 \%$ cholesterol; $0.3 \%$ chelate and $0.2 \%$ methylthiouracil 7 . All the mice were fed for four weeks, whereupon the mice of the fatty model group were randomly divided into 5 groups of 10 animals each, referred to as the fatty control model, $\mathrm{V}_{\mathrm{E}}$, and three oat rice wine groups (low, medium and high dosages). The mice of the normal control group were fed with basic forage continuously and given physiological saline at a dose of $0.3 \mathrm{ml}$ per rat by gavage daily. Mice in the $\mathrm{V}_{\mathrm{E}}$ group were administered with $\mathrm{V}_{\mathrm{E}}$ at a dose of $25.0 \mathrm{mg} \mathrm{kg} \mathrm{m}^{-1}$ b.w. by gavage daily (the dose was based on the antioxidant capacity). Mice in the oat rice wine groups of low, medium and high dosages were administered with oat rice wine at doses of $0.1,0.3$ and $0.6 \mathrm{ml}$, respectively, by gavage daily. Oral administration was performed between 8:00 and 9:30 a.m. daily and the animals were weighed every five days. After 4 weeks of gastric perfusion, all mice were fasted for $12 \mathrm{~h}$ and anesthesia was used to minimize pain, discomfort, and shock before the operation. Blood samples were obtained in the mice eyes during the operation and the specimen serum was kept at $-20^{\circ} \mathrm{C}$ until analysis. Meanwhile, murine liver samples were rapidly excised, weighed and frozen in fluid nitrogen and stored in a ultra-low temperature refrigerator $\left(-80^{\circ} \mathrm{C}\right)$ or fixed in $4 \%$ buffered formaldehyde solution until analysis.

\section{Preparation of blood serum and tissue samples}

All mice were cared for according to the Guiding Principles in the Care and Use of Animals of Xi'an Jiaotong University. At the end of the experiment, blood samples of mice in each group were collected by extirpating their eyes, whereupon the livers were immediately excised. After storing at room temperature for $2 \mathrm{~h}$, the upper serum was stored at $-20^{\circ} \mathrm{C}$ and the blood samples collected into tubes were centrifuged at 3,000 $\times \mathrm{g}$ for $10 \mathrm{~min}$ to separate the serum. The livers, washed with ice-cold physiological saline solution, were frozen in $-173^{\circ} \mathrm{C}$ in liquid nitrogen and then stored at $-80^{\circ} \mathrm{C}$. Part of the liver tissue was cut into pieces and milled to prepare a $100 \mathrm{~g} \mathrm{l}^{-1}$ suspension of tissue homogenate in a buffer of monobasic potassium phosphate and potassium phosphate dibasic. This tissue homogenate was centrifuged at 4,000 $\times \mathrm{g}$ for $15 \mathrm{~min}$ and the supernatant was kept for analysis. The tissue samples of livers and the serum of all mice were used to measure the enzyme activities of SOD, GSH-PX, AST and ALT, and the value of MDA.

\section{Antioxidant activity of the oat rice wine in vivo}

The protein contents of the different blood serum and tissue samples were measured using a coomassie (Bradford) protein assay kit. The MDA level was determined using an MDA assay kit A003 based on the Esterbauer $^{6}$ and Cheeseman method. SOD activity was determined with an SOD assay kit A001 according to Oyanagui's method ${ }^{21}$. GSH-PX activity was determined using a GSH-PX assay kit A005 ${ }^{22}$. All kits were purchased from the Institute of Biological Engineering of Nanjing Jianchen, Nanjing, China.

\section{Blood lipid and ALT, AST activities in vivo}

Serum total cholesterol (TC) and triglyceride (TG) concentrations were determined using a commercial kit ${ }^{12,15,23}$, while ALT and AST activities in serum were measured using a commercially available $\mathrm{kit}^{10}$ (Asan, Jianchen, Nanjing, China) .

\section{Statistical analyses}

Statistical analyses were run using SPSS 18.0 software, with data expressed as mean and standard deviations. Data were subjected to one-way analysis of variance (ANOVA). Duncan's multiple range test was used to determine the differences among means and results were considered statistically significant at $\mathrm{p}<0.05$.

\section{Results and discussion}

\section{Antioxidant activities of oat rice wine in vitro}

Fig. 1 shows that the content of polyphenols in oat 
rice wine $\left(153.74 \mu \mathrm{g} \mathrm{ml}^{-1}\right)$ exceeded that of the glutinous rice wine $\left(112.26 \mu \mathrm{g} \mathrm{ml}^{-1}\right)$ and polyphenol was found to be a very effective antioxidant constituent. It was reported that glutinous rice wine had the strongest antioxidant activity and the highest content of phenolic compounds compared to the other four Chinese rice wines (Guyuelongshan, Hongqu, Shousheng and Foshou $)^{9}$.

The result of the antioxidant inhibition ratio (the value is 1- the absorption value of the complex with rice wine/the absorption value of the black) of oat rice wine, glutinous rice wine and BHA on the fifth day of the reaction was shown in Fig. 2. The antioxidant inhibition ratios all exceeded $97 \%$. The inhibition ratio of oat rice wine was the highest while the glutinous rice wine was the lowest among the three systems $(p<0.05)$.

The reducing capacity was used to measure the antioxidant activity according to a study showing that antioxidants could reduce the ferric ion complex to the fer-

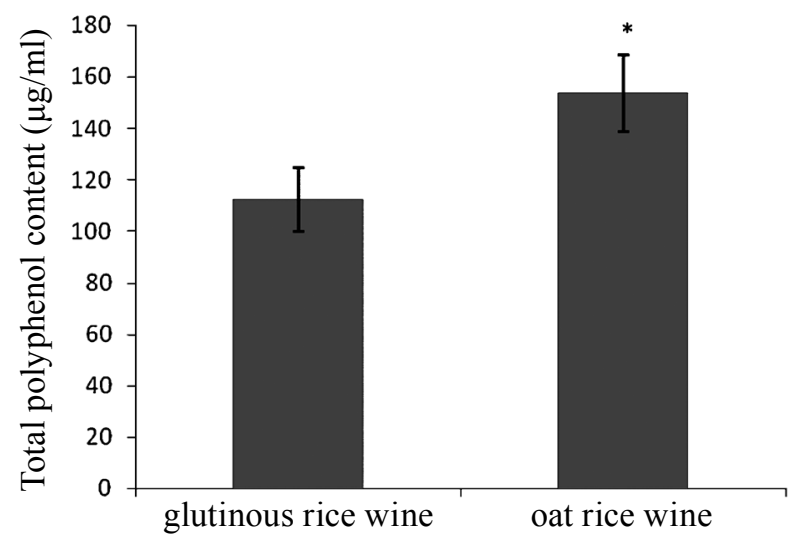

Fig. 1. Contents of polyphenol in different rice wine Within each column, an asterisk indicates statistically different values according to Duncan's multiple range test at $\mathrm{p}<0.05$.

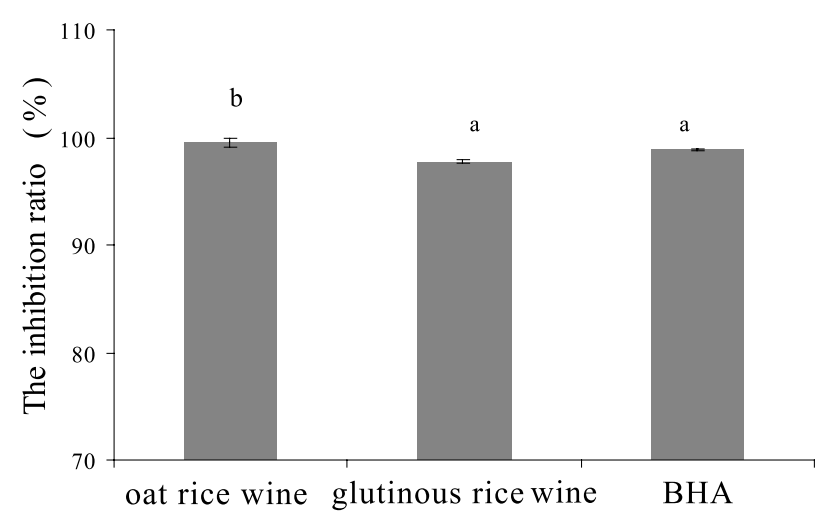

Fig. 2. Inhibition ratio of rice wine to linoleic acid oxidation (5 d)

Values represent the mean $\pm \operatorname{sd}(n=3)$.

${ }^{\mathrm{a}} \mathrm{p}<0.05$ VS glutinous rice wine, ${ }^{\mathrm{b}} \mathrm{p}<0.05$ VS glutinous rice wine rous form. Antioxidant activity was expressed as the increase in absorbance. As shown in Fig. 3, reducing power rose with increasing concentration in both rice wines, while oat rice wine showed significantly higher reducing power than glutinous rice wine at dosages of 50, 100 and $150 \mu \mathrm{l}(\mathrm{p}<0.05)$. As shown in Fig. 4, the metal chelating capacity of rice wine was poor compared to EDTA and citric acid. However the metal chelating capacity rose with increasing concentrations of both rice wines, while oat rice wine was stronger than glutinous rice wine at dosages of 500 and $1000 \mu 1(p<0.05)$. Metal chelating capacity is assumed to be one parameter of antioxidant activity, since it reduces the concentration of the catalyzing transition metal in lipid peroxidation. It was

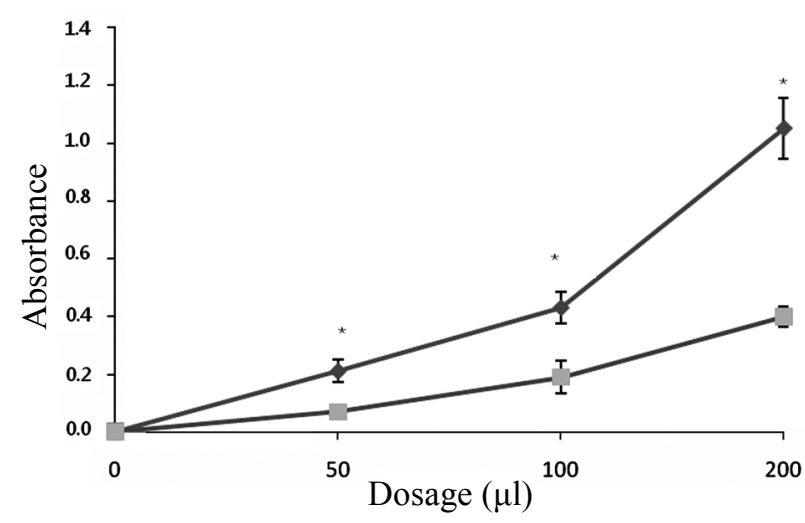

Fig. 3. Reducing capacity of oat rice wine and glutinous rice wine

Values represent the mean $\pm \operatorname{sd}(n=3)$.

An asterisk indicates statistically different values according to Duncan's multiple range test at $\mathrm{p}<$ 0.05 .

$\neg$ : oat rice wine, $\_-$: Glutinous rice wine.

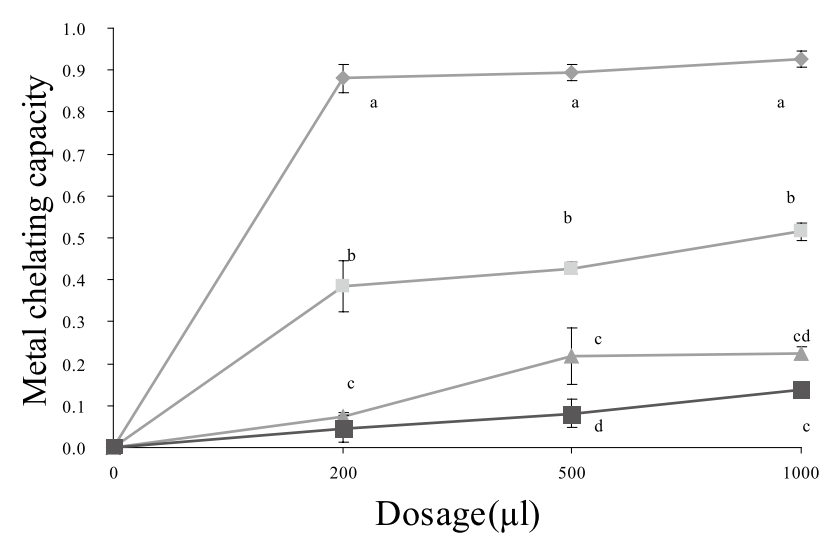

Fig. 4. Metal chelating capacity of oat rice wine and glutinous rice wine

Values represent the mean $\pm \mathrm{sd}(\mathrm{n}=3)$.

${ }^{\mathrm{b}} \mathrm{p}<0.05$ VS EDTA, ${ }^{\mathrm{bc}} \mathrm{p}<0.05$ VS EDTA, ${ }^{\mathrm{c}} \mathrm{p}<0.05$ VS EDTA

$\rightarrow$ : EDTA, $-\square$ : citric acid, $\neg$ : oat rice wine, $\rightarrow-$ : glutinous rice wine. 
reported that chelating agents, which formed s-bonds with metal, were effective as secondary antioxidants since they stabilized the oxidized form of the metal ion by reducing the redox potential ${ }^{31}$.

\section{Antioxidant activities of oat rice wine in vivo}

Table 1 demonstrated that there was no significant difference in SOD activities between the oat rice wine and normal control groups $(\mathrm{p}<0.05)$ in the blood serum of mice. The GSH-PX activities in the medium and high oat rice wine groups exceeded that of the fatty control group $(p<0.05)$, and showed no significant difference with the $\mathrm{V}_{\mathrm{E}}$ group, which meant oat rice wine at a medium or high dose could promote GSH-PX activity in the blood serum of mice. MDA content is a good indicator of lipid peroxidation ${ }^{24}$. Compared to the fatty model group, the MDA value of all three oat rice wine groups was evidently decreased ( $p<0.05)$, suggesting that oat rice wine clearly reduces the degree of lipid peroxidation in blood serum. However, the effects of concentrations of oat rice wine on MDA, SOD and GSH-PX values were insignificant.

From Table 2, there was no significant difference among the oat rice wine groups and fatty model groups in terms of SOD activities in the liver $(\mathrm{p}<0.05)$. For medium and high doses, the GSH-PX values of oat rice wine were evidently higher $(p<0.05)$ than that of the fatty model group, which was similar to $\mathrm{V}_{\mathrm{E}}$. The results suggested that oat rice wine could improve the GSH-PX activity but not the SOD activities of liver in mice. The MDA contents of all oat rice wine groups were lower than those of the fatty group $(\mathrm{p}<0.05)$ in the liver, but not evidently different $(p>0.05)$ from $V_{E}$ and normal control groups. This result indicates that oat rice wine had a strong ability to reduce MDA content in the liver, similar to $\mathrm{V}_{\mathrm{E}}$.

In this work, we used a high-fat diet to set up the fatty model. The fatty model induced hepatic damage in the mice by reducing SOD and GSH-PX activities in the liver and blood serum compared with the control, which correlated with the results of former studies ${ }^{27}$. It was demonstrated that SOD and GSH-PX activities of the oat rice wine groups increased in both blood serum (Table 1) and the liver (Table 2), while the MDA values of the oat rice wine groups decreased comparing with the fatty model. This result indicates that all oat rice wine groups have antioxidant activity, which improved the situation of the liver more or less. As for $\mathrm{V}_{\mathrm{E}}$, which is one of the most popular natural phenolic type antioxidants ${ }^{13}$, the antioxidant activity of oat rice wine was weaker than $\mathrm{V}_{\mathrm{E}}(25.0 \mathrm{mg}$ $\mathrm{kg}^{-1}$ ).

It was reported that the MDA content on mice serum at high doses $\left(0.6 \mathrm{ml} \mathrm{d}^{-1}\right)$ of xiaogan rice wine made of glutinous was $14.43 \pm 1.60 \mathrm{n} \mathrm{mol} \mathrm{ml}^{-1}$, which exceeded that

Table 1. Effect of oat rice wine on mice serum MDA, SOD and GSH-PX activities

\begin{tabular}{lccc}
\hline \hline GROUPS & SOD $\left(\mathrm{U} \mathrm{ml}^{-1}\right)$ & GSH-PX $\left(\mathrm{U} \mathrm{ml}^{-1}\right)$ & MDA $\left(\mathrm{n} \mathrm{mol} \mathrm{ml}{ }^{-1}\right)$ \\
\hline Normal control group & $198.85 \pm 15.21^{\mathrm{ab}}$ & $282.42 \pm 18.83^{\mathrm{a}}$ & $9.36 \pm 1.89^{\mathrm{c}}$ \\
Fatty control model & $174.17 \pm 17.44^{\mathrm{b}}$ & $244.46 \pm 13.84^{\mathrm{c}}$ & $16.74 \pm 1.40^{\mathrm{a}}$ \\
Oat rice wine (low) & $184.28 \pm 23.88^{\mathrm{ab}}$ & $258.19 \pm 11.2^{\mathrm{bc}}$ & $12.16 \pm 1.27^{\mathrm{bc}}$ \\
Oat rice wine (medium) & $195.82 \pm 15.39^{\mathrm{ab}}$ & $272.46 \pm 24.5^{\mathrm{ab}}$ & $14.11 \pm 2.39^{\mathrm{b}}$ \\
Oat rice wine (high) & $189.305 \pm 9.26^{\mathrm{ab}}$ & $275.1 \pm 12.43^{\mathrm{ab}}$ & $13.64 \pm 3.01^{\mathrm{b}}$ \\
$\mathrm{V}_{\mathrm{E}}$ & $205.61 \pm 14.10^{\mathrm{a}}$ & $261.69 \pm 17.92^{\mathrm{b}}$ & $10.24 \pm 2.98^{\mathrm{c}}$ \\
\hline
\end{tabular}

All data are expressed as mean $\pm \mathrm{sd}(\mathrm{n}=10)$.

Different superscripts in the same column mean significant differences $(p<0.05)$.

Table 2. Effect of oat rice wine on mice liver MDA, SOD and GSH-PX activities

\begin{tabular}{lccc}
\hline \hline GROUPS & SOD $\left(\mathrm{U} \mathrm{ml}^{-1}\right)$ & GSH-PX $\left(\mathrm{U} \mathrm{ml}^{-1}\right)$ & MDA $\left(\mathrm{n} \mathrm{mol} \mathrm{ml}^{-1}\right)$ \\
\hline Normal control group & $116.70 \pm 12.97^{\mathrm{a}}$ & $329.60 \pm 14.3^{\mathrm{a}}$ & $2.04 \pm 0.26^{\mathrm{ab}}$ \\
Fatty control model & $81.81 \pm 12.61^{\mathrm{b}}$ & $203.98 \pm 13.4^{\mathrm{c}}$ & $2.21 \pm 0.24^{\mathrm{a}}$ \\
Oat rice wine (low) & $82.27 \pm 7.91^{\mathrm{ab}}$ & $246.22 \pm 14.7^{\mathrm{b}}$ & $1.68 \pm 0.33^{\mathrm{b}}$ \\
Oat rice wine (medium) & $86.89 \pm 8.23^{\mathrm{ab}}$ & $278.6 \pm 17.2^{\mathrm{ab}}$ & $1.78 \pm 0.24^{\mathrm{b}}$ \\
Oat rice wine (high) & $89.96 \pm 11.44^{\mathrm{ab}}$ & $267.79 \pm 17.54^{\mathrm{ab}}$ & $1.70 \pm 0.26^{\mathrm{b}}$ \\
$\mathrm{V}_{\mathrm{E}}$ & $111.86 \pm 11.7^{\mathrm{a}}$ & $257.82 \pm 12.4^{\mathrm{b}}$ & $1.66 \pm 0.29^{\mathrm{b}}$ \\
\hline
\end{tabular}

All data are expressed as mean $\pm \mathrm{sd}(\mathrm{n}=10)$.

Different superscripts in the same column mean significant differences $(\mathrm{p}<0.05)$ 
of oat rice wine ${ }^{16}$. From Yao Ping's research, with the conversion, the intake of ethanol, at a dose of $0.5 \mathrm{ml} \mathrm{d}^{-1}$ for 30 days, could significantly influence the antioxidant system $^{32}$, whereby the SOD activities $\left(78.6 \pm 8.1 \mathrm{U} \mathrm{ml}^{-1}\right)$ were lower than those of oat rice wine. This showed that oat rice wine had better antioxidant effects compared to regular rice wine and ethanol.

The changes in enzyme activities may be attributed to the absorption and metabolism of antioxidant components in oat rice wine. Phenolic acids are believed mainly to act as free radical scavengers or chelators of transition metals ${ }^{24}$. High-fat diets reportedly increase the oxidative stress on various tissues, which may produce more reactive oxygen species (ROS) and result in many degenerative disease ${ }^{14}$. Meanwhile, the antioxidant ability in vivo was mostly demonstrated on antioxidant enzymes and by inhibiting lipid peroxidation, which were capable of eliminating active oxygen species, to protect tissues and organs from oxidative damage ${ }^{24}$. It could be concluded that a high dose of oat rice wine may be better to increase antioxidant ability. The relatively stronger effect of oat rice wine at high doses may be attributable to a superior intake of antioxidant compounds such as polyphenols in the diet, because of the high correlation between concentrations of polyphenols and the antioxidant activity.

\section{Blood lipid and the ALT, AST activities in vivo}

In this work, the TG content fell with increasing oat rice wine dose and the high dose oat rice wine group obviously reduced it $(\mathrm{p}<0.05)$ in serum (Table 3$)$. Similarly, high dose oat rice wine also significantly decreased the TC content $(\mathrm{p}<0.05)$ in serum (Table 3$)$. As a high-fat diet could increase impairments in blood lipid regulation ${ }^{3}$ and high cholesterol diets increased serum TC levels, resulting in an increased risk for the development of arteriosclerosis ${ }^{30}$, our results suggested that high oat rice wine worked well to inhibit the latter. Furthermore, oat rice wine improved lipid profiles by lowering total plasma cholesterol concentration and triglyceride concentrations compared to the fatty control group. Phenolic compounds reportedly functioned to suppress dyslipidemia and hepatosteatosis ${ }^{19}$. The strong effect expressed by the high dose oat rice wine may be due to the ingestion of arteriosclerosis elements, such as phenolic compounds from oat rice wine.

The measurement of plasma ALT and AST activities showed a level of hepatic damage in the high cholesterolinduced fatty liver ${ }^{26}$. The enzyme activities of the ALT and AST in oat rice wine groups were significantly lower $(\mathrm{p}<0.05)$ than the fatty control groups, both in serum (Table 3 ) and the liver (Table 4). From Table 3, The ALT activities of oat rice wine groups at medium and high doses were evidently lower $(p<0.05)$ than those of the fatty control group, and showed no significant difference $(\mathrm{p}>$ 0.05 ) from the $\mathrm{V}_{\mathrm{E}}$ and normal control groups. With regard to AST activities, all three oat rice wine groups, the $\mathrm{V}_{\mathrm{E}}$ group and normal control group showed no significant difference among each other $(\mathrm{p}>0.05)$.

It could be concluded that a medium dose of oat rice wine led to the lowest ALT and AST values, suggesting that this had the best effect in terms of preventing liver damage during this study. This may be ascribed to the balance of the beneficial effect from the functional com-

Table 4. Effect of oat rice wine on mice liver ALT and AST levels

\begin{tabular}{lcl}
\hline \hline GROUPS & ALT $\left(U \mathrm{Ul}^{-1}\right)$ & AST $\left(\mathrm{U} \mathrm{ml}^{-1}\right)$ \\
\hline Normal control group & $89.7 \pm 14.2^{\mathrm{ab}}$ & $46.1 \pm 11.7^{\mathrm{ab}}$ \\
Fatty control model & $92.38 \pm 12.05^{\mathrm{a}}$ & $65.2 \pm 16.57^{\mathrm{a}}$ \\
Oat rice wine (low) & $76.85 \pm 8.50^{\mathrm{bc}}$ & $35.9 \pm 6.9^{\mathrm{b}}$ \\
Oat rice wine (medium) & $68.32 \pm 5.70^{\mathrm{c}}$ & $31.1 \pm 6.6^{\mathrm{b}}$ \\
Oat rice wine (high) & $81.12 \pm 14.06^{\mathrm{bc}}$ & $41.8 \pm 12.7^{\mathrm{ab}}$ \\
$\mathrm{V}_{\mathrm{E}}$ & $77.33 \pm 6.71^{\mathrm{b}}$ & $31.5 \pm 4.6^{\mathrm{b}}$ \\
\hline
\end{tabular}

All data are expressed as mean $\pm \mathrm{sd}(\mathrm{n}=10)$.

Different superscript in same column meant significantly different $(\mathrm{p}<0.05)$.

Table 3. Effect of oat rice wine on mice serum TC, TG, ALT and AST levels

\begin{tabular}{lcccc}
\hline \hline GROUPS & TG $(\mathrm{m} \mathrm{mol} / \mathrm{l})$ & TC $(\mathrm{m} \mathrm{mol} / \mathrm{l})$ & ALT $\left(\mathrm{U} \mathrm{ml}^{-1}\right)$ & AST $\left.(\mathrm{U} \mathrm{ml})^{-1}\right)$ \\
\hline Normal control group & $0.97 \pm 0.36^{\mathrm{ab}}$ & $5.79 \pm 0.83^{\mathrm{ab}}$ & $33.32 \pm 6.95^{\mathrm{b}}$ & $89.06 \pm 13.31^{\mathrm{b}}$ \\
Fatty control model & $1.3 \pm 0.51^{\mathrm{a}}$ & $6.16 \pm 0.79^{\mathrm{a}}$ & $54.85 \pm 3.57^{\mathrm{a}}$ & $122.98 \pm 29.7^{\mathrm{a}}$ \\
Oat rice wine (low) & $1.24 \pm 0.26^{\mathrm{a}}$ & $5.71 \pm 0.78^{\mathrm{ab}}$ & $43.33 \pm 8.5^{\mathrm{ab}}$ & $94.73 \pm 15.89^{\mathrm{b}}$ \\
Oat rice wine (medium) & $1.08 \pm 0.27^{\mathrm{ab}}$ & $6.05 \pm 0.75^{\mathrm{ab}}$ & $32.52 \pm 7.54^{\mathrm{b}}$ & $80.78 \pm 13.04^{\mathrm{b}}$ \\
Oat rice wine (high) & $0.75 \pm 0.08^{\mathrm{b}}$ & $5.20 \pm 0.74^{\mathrm{b}}$ & $41.33 \pm 12.46^{\mathrm{b}}$ & $96.08 \pm 13.7^{\mathrm{b}}$ \\
$\mathrm{V}_{\mathrm{E}}$ & $1.01 \pm 0.19^{\mathrm{ab}}$ & $5.66 \pm 0.75^{\mathrm{ab}}$ & $35.8 \pm 11.61^{\mathrm{b}}$ & $98.83 \pm 16.47^{\mathrm{b}}$ \\
\hline
\end{tabular}

All data are expressed as mean $\pm \mathrm{sd}(\mathrm{n}=10)$.

Different superscripts in the same column mean significant differences $(\mathrm{p}<0.05)$. 
pounds and the negative impact of alcohol on oat rice wine. Heavy chronic alcohol intake resulted in marked steatosis and enhanced the hepatic deposition of complement components ${ }^{11}$. Moreover, monascus-fermented rice represented a strategy to protect against alcoholic liver disease by attenuating oxidative stress, inflammatory response, and steatosis ${ }^{4}$. With the increased dose of oat rice wine, the concentration of compositions which alleviate and exacerbate fatty liver was enhanced. Consequently, the balance was destroyed and superior alcohol intake would damage the liver.

\section{Conclusions}

The evident antioxidant activities of oat rice wine in vitro were confirmed by high contents $\left(153.74 \mu \mathrm{g} \mathrm{ml}^{-1}\right)$ of polyphenols, stronger metal chelating capacity and the reducing power and inhibitory capacity of lipid peroxidation compared to glutinous rice wine. Oat rice wine increased SOD and GSH-PX activities, while decreasing MDA contents in blood serum and liver of the fatty model mice. For blood lipid contents, oat rice wine decreased TG and TC contents in the serum. At a high dose of 0.6 $\mathrm{ml} \mathrm{d}^{-1}$, oat rice wine showed the strongest activity in terms of inhibiting atherosclerosis and lipid peroxidation. With regard to the enzyme activities of AST and ALT, oat rice wine reduced both. The results suggested that oat rice wine was beneficial for fatty liver and a medium dose of $0.3 \mathrm{ml} \mathrm{d}^{-1}$ appeared most effective in ameliorating liver damage.

\section{Acknowledgements}

The research is supported by the China Agriculture Research System (CARS-08-D-3). The authors acknowledge Professor Hu Xinzhong (Northwest Agriculture and Forestry University) for help with the animal experiments.

\section{References}

1. Cai, S. et al. (2011) In vitro antioxidant activity and inhibitory effect, on oleic acid-induced hepatic steatosis, of fractions and subfractions from oat (Avena sativa L.) ethanol extract. Food Chem., 124, 900-905.

2. Chen, H. et al. (1995) Structure analysis of antioxidative peptides from soybean $\beta$-conglycinin. J. Agric. Food Chem., 43, 574-578.

3. Chen, H. et al. (2010) Effect of soybean oligosaccharides on blood lipid, glucose levels and antioxidant enzymes activity in high fat rats. Food Chem., 119, 1633-1636.

4. Cheng, C. et al. (2011) Protective Effect of Monascus-Fermented Red Mold Rice against Alcoholic Liver Disease by Attenuating Oxidative Stress and Inflammatory Response.
J. Agric. Food Chem., 59, 9950-9957.

5. Decker, E. et al. (1990) Role of ferritin as a lipid oxidation catalyst in muscle food. J. Agric. Food Chem., 38, 674-677.

6. Dong, H. et al. (2005) Effects of emodin on treating murine nonalcoholic fatty liver induced by high caloric laboratory chaw. World J Gastroentero, 11, 1339-1344.

7. Esterbauer, H. et al. (1990) Determination of aldehydic lipid peroxidation products: malonaldehyde and 4-hydroxynonenal. Method Enzymol., 186, 407-421.

8. Fei, Qu. et al. (2006) Antioxidant properties of Chinese yellow wine, its concentrate and volatiles. Swiss Society of Food Science and Technology, 39,111-117.

9. Fei, Q. et al. (2006) Antioxidant activities of five Chinese rice wines and the involvement of phenolic compounds. Food Res. Int., 39, 581-587.

10. Folch, J. et al. (1957) A simple method for isolation and purification of total lipids from animal tissues. J. Biol. Chem., 226, 497-509.

11. Igor, L. et al. (2004) Protective function of complement against alcohol-induced rat liver damage. Int. Immunopharmacol., 4, 1445-1454.

12. Krynski, I. et al. (1968) Observations on diagnostic kits for the determination of total cholesterol. Clin. Biochem., 2, 105-114.

13. Li, C. et al. (2007) Protective effect of paeoniflorin on irradiation-induced cell damage involved in modulation of reactive oxygen species and the mitogen-activated protein kinases. J. Biochem., 39, 426-438.

14. Ma, M. et al. (2009) Effect of the Lycium barbarum polysaccharides administration on blood lipid metabolism and oxidative stress of mice fed high-fat diet in vivo. Food Chem., 113, 872-877.

15. McGowan, M. et al. (1983) A peroxidase-coupled method for the colorimetric determination of serum triglycerides. Clin. Chem., 29, 538-542.

16. Meng, Z. et al. (2011) Effects of Xiaogan Rice Wine on Memory and Antioxidation Function of Mice. Animal Husbandry and Feed Science, 32, 1-2.

17. Mitsuda. et al. (1966) Antioxidation action of indole compounds during the autoxidation of linoleic acid. Eiyo to Shokuryo, 19, 210-214.

18. Mohan, A. et al. (2007) Isolation and characterization of dihydromonacolin-MV from Monascus purpureus for antioxidant properties. Appl. Microbiol. Biotechnol., 73, 11971202.

19. Niho, N. et al. (2001) Subchronic toxicity study of gallic acid by oral administration in F344 rats. Food Chem. Toxicol., 39, 1063-1070.

20. Oyaizu, M. (1986) Studies on products of browning reaction prepared from glucoseamine. Japan J. Nutr., 44, 307314.

21. Oyanagui, Y. (1984) Reevaluation of assay methods and establishment of kit for superoxide dismutase activity. Anal. Biochem., 142, 290-296.

22. Paglia, D. et al. (1967) Studies on the quantitative and qualitative characterization of erythrocyte glutathione peroxidase. J. Lab Clin. Med., 70, 158-169.

23. Pasin, G. et al. (1996) Rapid determination of total cholesterol in egg yolk using commercial diagnostic cholesterol reagent. Food Chem., 61, 255-259.

24. Qiu, J. et al. (2010) Antioxidant activities of aged oat vine- 
gar in vitro and in mouse serum and liver. J. Sci. Food Agric., 90, 1951-1958.

25. Veronica, H. et al. (1995) The cholesterol-lowering effect of oat bran cereals in rats: Influence of processing. Nutritional Biochem., 6, 246-249.

26. Victoria, G. et al. (2003) Effects of dietary beta-cyclodextrin in hypercholesterolaemic rats. Pharmacol. Toxicol., 92, 94-99.

27. Wang, D. et al. (2008) In vitro and in vivo studies on the antioxidant activities of the aqueous extracts of Douchi (a traditional Chinese salt-fermented soybean food). Food Chem., 107, 1421-1428.

28. Wang, J. (1998) The nutrition value and health care function of yellow wine. China Brewing, 98, 34-35.

29. Wolfe, K. et al. (2003) Antioxidant activity of apple peels.
J. Agric. Food Chem., 51, 609-614.

30. Woo, M. et al. (2009) Hypolipidemic and body fat-lowering effects of Fatclean in rats fed a high-fat diet. Food Chem. Toxicol., 47, 2076-2082.

31. Yamaguchi, F. et al. (2000). Antioxidant and anti-glycation of carcinol from Garcinia indica fruit rind. J. Agric. Food Chem., 48, 180-185.

32. Yao, P. et al. (2007) The Dynamic Dose Response of Rat Serum Antioxidant System to Alcohol and The Preventive Effect of Ginkgetin. Acta. Nutrimenta Sinica., 29, 166-170.

33. Zhang, X. (2004) How to make distiller's yeast for Chinese yellow wine. China Condiment, 121, 33-34.

34. Zhang, Z. et al. (1999) The brewing technology development of yellow wine. Liquor Making, 13, 45-47. 